\title{
Neuropeptides Phase Shift the Mammalian Circadian Pacemaker
}

\author{
Hugh D. Piggins, ${ }^{1,3}$ Michael C. Antle, ${ }^{1}$ and Benjamin Rusak ${ }^{1,2}$ \\ Departments of ${ }^{1}$ Psychology, ${ }^{2}$ Pharmacology, and ${ }^{3}$ Anatomy and Neurobiology, Dalhousie University, Halifax, Nova \\ Scotia, Canada B3H 4J1
}

We studied the influence on circadian rhythms of peptides that have been reported to be colocalized in suprachiasmatic nucleus (SCN) neurons. Gastrin-releasing peptide (GRP $_{1-27}$ ), peptide histidine isoleucine (PHI), and vasoactive intestinal polypeptide (VIP) were microinjected into the suprachiasmatic nucleus (SCN) region of Syrian hamsters free running under three different constant lighting conditions. All peptide injections caused phase-dependent phase shifts of hamster locomotor activity rhythms which were unaffected by constant lighting conditions. GRP $_{1-27}$ (150 pmol) caused large phase delays when injected at circadian times (CT) 12-16, modest phase advances when administered at CT20-24, and few shifts during the subjective day. Injectlons of saline vehicle at any of these phases caused only very small phase shifts. Phase delays induced by GRP $_{1-27}$ at CT12-14 were dose dependent, unrelated to injection volume (at a constant dose), and attenuated by pretreatment with the BN/GRP-preferring receptor antagonist BIM 26226. VIP ( 150 pmol) caused moderate phase delays at $\mathrm{CT} 12-14$ and moderate phase advances at CT2O24. PHI (150 pmol) caused moderate phase delays at CT1214 only. Coadministration of 150 pmol of $\mathrm{GRP}_{1-27}, \mathrm{PHI}$, and VIP in an equimolar neuropeptide cocktail ( 50 pmol of each peptide) caused phase delays at CT12-14 and phase advances at CT20-24 which did not differ from those induced by 150 pmol of GRP $_{1-27}$ alone at these phases. The shifts induced by 150 pmol of the peptide cocktail were smaller than the sum of the shifts induced by 50 pmol doses of each peptide administered separately at those phases. Since the phase-delaying effects of the cocktail were weaker than the summed effects of the component 50 pmol doses of the peptides, these data demonstrate a lack of synergism among the effects of these peptides. Since GRP ${ }_{1-27}$ (150 pmol) evoked shifts similar in magnitude to those of the cocktail, there is no evidence that these apparently colocalized neuropeptides must interact to exert maximal effects on the circadian pacemaker.

[Key words: gastrin-releasing peptide, peptide histidine

\footnotetext{
Received Feb. 14, 1995; revised Mar. 30, 1995; accepted Apr. 4, 1995

This research was supported by grants from the US Air Force Office of Scientific Research (F49620-93-1-0089), and the Natural Sciences and Engineering Research Council of Canada (NSERC: A0305). H.D.P. was supported by postdoctoral fellowships from NSERC and the Medical Research Council of Canada. We thank Donna Goguen, Heather Grant, and Victoria Muise for their excellent technical assistance. BIM 26226 was a gift from Dr. J. Taylor of Biomeasure Inc.

Correspondence should be addressed to Dr. Hugh D. Piggins, Department of Psychology, Life Sciences Centre, Dalhousie University, Halifax, Nova Scotia, Canada B3H $4 \mathbf{J}$ I.

Copyright $(\mathcal{C} 1995$ Society for Neuroscience $0270-6474 / 95 / 155612-11 \$ 05.00 / 0$
}

isoleucine, vasoactive intestinal polypeptide, suprachiasmatic nucleus, circadian rhythm, entrainment, neuropeptide, phase shift, constant light, constant dark]

Colocalization of neuroactive substances in single neurons has been demonstrated in many parts of the central and peripheral nervous systems. Although direct evidence for the functional implications of this phenomenon is rare, it has been proposed that colocalized neuropeptides can interact to modulate neuroactivity. This interaction may take many forms, including (but not limited to) modulation by one substance of postsynaptic receptor responses to another, inhibition of catabolic enzymes, presynaptic regulation by one substance of the release of other neurotransmitters, and alterations in presynaptic reuptake mechanisms (Kupfermann, 1991; Bean et al., 1994).

One area of the hypothalamus in which ncuropeptides are thought to be colocalized is the suprachiasmatic nucleus (SCN). The SCN contains the primary mammalian circadian pacemaker (Rusak and Zucker, 1979; Meijer and Rietveld, 1989). This pacemaker is entrained by photic information received through the visual pathways innervating the $\mathrm{SCN}$, the retinohypothalamic tract (RHT) (Moore, 1973; Pickard, 1982; Johnson et al., 1988), and the geniculohypothalamic tract (GHT) (Swanson et al., 1974; Harrington and Rusak, 1986; Zhang and Rusak, 1989).

Both immunocytochemical and in situ hybridization studies indicate that cells and terminals of the rodent SCN contain a number of neuropeptides including gastrin-releasing peptide $\left(\mathrm{GRP}_{1-27}\right)$, peptide histidine isoleucine (PHI), somatostatin, substance P, vasoactive intestinal polypeptide (VIP), and vasopressin (VP) (Lorén et al., 1979; Moody et al., 1981; Roth et al., 1982; Card and Moore, 1984; Panula et al., 1984; Okamura et al., 1986; van den Pol and Gores, 1986; Wada et al., 1989; Dussaillant et al., 1992; Gundlach and Knobe, 1992; Kalsbeek et al., 1993). Colocalization of mRNA and protein immunoreactivity (-ir) for $\mathrm{GRP}_{1-27}, \mathrm{PHI}$, and VIP have been demonstrated in some cells in the ventrolateral aspect of the rat SCN (Okamura et al., 1986; Albers et al., 1991). High levels of receptor mRNA and high grain densities of binding sites for these peptides have also been demonstrated in the rat SCN (Shaffer and Moody, 1985; Besson et al., 1986; Martin et al., 1987; Moody et al., 1988; Ladenheim et al., 1990, 1992, 1993; Battey and Wada, 1991; Hill et al., 1994; Usdin et al., 1994), implicating their local release in the modulation of neuronal activity in the rat $\mathrm{SCN}$. However, the functional correlates of this colocalization are unknown.

A previous report claimed that $\mathrm{GRP}_{1-27}$, PHI, and VIP interact synergistically to produce maximal postsynaptic effects on SCN cellular activity and function (Albers et al., 1991). Individually, $\mathrm{GRP}_{1-27}, \mathrm{PHI}$, or VIP evoked only small activations in hamster 
SCN neuronal activity in vitro, while a cocktail containing equimolar doses of all three of these neuropeptides induced large increases in the spontaneous firing rate. In parallel investigations, microinjections of $\mathrm{GRP}_{1-27}$, PHI, or VIP alone into the SCN of hamsters free running in constant, bright light (LL) conditions produced only small phase shifts in the locomotor activity rhythm, while microinjection of the neuropeptide cocktail produced very large phase delays. These studies indicate that $\mathrm{GRP}_{1-27}, \mathrm{PHI}$, or VIP alone have minimal effects on rodent SCN neuronal activity, but their collective interaction produces maximal effects on the circadian pacemaker. These results have been cited frequently as providing critical support for a model which proposes that colocalization and co-release of these peptides are essential for them to play their functional role in the entrainment of circadian rhythms (Albers et al., 1991; Peters et al., 1994).

Attempts to replicate these neurophysiological results have not, however, been successful. A number of studies have found that $\mathrm{GRP}_{1-27}$ alone can potently alter rodent SCN neuronal activity in vitro. Bath applications of $\mathrm{GRP}_{1-27}$ depolarized rat $\mathrm{SCN}$ cells, while local applications of $\mathrm{GRP}_{1-27}$ (and related analogs) by pressure ejection or iontophoresis activated hamster SCN cells (Piggins and Rusak, 1993a; Tang and Pang, 1993; Piggins et al., 1994b; Pinnock et al., 1994). The effects of $\mathrm{GRP}_{1-27}$ analogs on rodent SCN cells appear to be specific and receptor mediated, since they were blocked or attenuated by GRP-preferring receptor antagonists. Since these results contradicted the earlier claim in showing that $\mathrm{GRP}_{1-27}$ alone has large effects on rodent $\mathrm{SCN}$ cells, it became important to reexamine the proposed functional interactions among these peptides.

We have therefore reexamined the hypothesis that $\mathrm{GRP}_{1-27}$, PHI, and VIP interact to exert a maximal effect on the hamster circadian pacemaker. We did this by first examining the phaseshifting properties of $\mathrm{GRP}_{\mathrm{I}-27}$, since this neuropeptide has been shown to be a potent activator of both rat and hamster SCN cells (Piggins and Rusak, 1993a; Tang and Pang, 1993; Piggins et al., 1994b; Pinnock et al., 1994). We then assessed the phase-shifting effects of PHI and VIP when administered alone or in combination with GRP ${ }_{1-27}$. In the first series of experiments, we established a phase-response curve for $\mathrm{GRP}_{1-27}$, and showed dose relatedness of $\mathrm{GRP}_{1-27}$-induced phase delays, blockade of these phase delays with a GRP ${ }_{1-27}$ receptor antagonist, and the independence of $\mathrm{GRP}_{1-27}$-induced phase shifts from injection volume or constant lighting conditions. In the second series of experiments, we evaluated the phase-shifting effects of PHI and VIP alone at two phases of the circadian cycle and the influence of constant lighting conditions on these phase shifts. We then compared the phase-shifting effects of $\mathrm{GRP}_{1-27}$, PHI, or VIP alone with the phase-shifting effects of a neuropeptide cocktail containing equimolar doses of all three of these neuropeptides.

Some of these results have been presented previously in abstract form (Piggins and Rusak, 1993b; Piggins et al., 1994a).

\section{Materials and Methods}

Animals. Adult male Syrian hamsters (LVG:lak) were obtained from Charles River Canada (St. Constant, Québec, Canada) and housed (with ad lib access to standard lab chow and water) in a colony room for at least $10 \mathrm{~d} \mathrm{on}$ a $24 \mathrm{hr}$ light:dark cycle (ID 14:10) at a ronm temperature of $\sim 20^{\circ} \mathrm{C}$. Animals were then transferred to test rooms equipped with cages containing running wheels and maintained in one of the following lighting conditions: constant dim red light (RR; illumination from a 10 W safelight equipped with either a Kodak GBX or GBX2 filter; light intensity at the center of the room $<0.1$ lux ); constant bright light (LL; illumination from a panel of Daylight fluorescent ubes; light intensity at the center of the room $\sim 300$ lux); or constant dark (DD; 0 lux).
Animals were allowed to free run under these conditions for 1-2 weeks. Each animal $(n-235)$ was then implanted stereotaxically with a 22 gauge stainless steel cannula (Plastics One, Roanoke, VA) cemented to the skull with dental acrylic under sodium pentobarbital anesthesia $(80$ $\mathrm{mg} / \mathrm{kg}$ ). The cannula was aimed at the SCN region [coordinates (adjusted slightly for body weight) $0.5 \mathrm{~mm}$ anterior to bregma, $0.2 \mathrm{~mm}$ lateral to the midline, and $7.3 \mathrm{~mm}$ ventral to the skull surface; incisor bar at $-2.0 \mathrm{~mm}$ ]. An obtruder (29 gauge) was inserted to extend 1.0 $\mathrm{mm}$ beyond the tip of the external guide cannula. Animals were injected with the analgesic buprenorphine $(0.5 \mathrm{mg} / \mathrm{kg})$ following recovery from the anesthetic.

GRP $_{1-27}$ (Bachem, Torrance, CA) or BIM 26226 (a gift of Dr. John Taylor, Biomeasure Inc., Milford, MA) was dissolved in physiological saline and injected through a 30 gauge stainless steel inner cannula, which was inserted to extend $1 \mathrm{~mm}$ below the end of the guide cannula. A volume of up to $1.0 \mu \mathrm{l}$ of either saline vehicle or $\mathrm{GRP}_{1-27}$ (up to 150 pmol) was injected using a 0.5 or $1.0 \mu$ l Hamilton syringe and PE20 tubing. Animals were injected repeatedly at different circadian phases using either drug or vehicle as long as they maintained stable freerunning rhythms (ranging from one to nine injections, with an average of four). Some animals contributed data to more than a single study, although each was maintained and tested in only one constant lighting condition.

In the first experiment, drug or vehicle solutions were injected at various phases of the circadian cycle to assess circadian variation in sensitivity to $\mathrm{GRP}_{1-27}$ and saline vehicle, as reflected in the phase-response curves (PRCs) that were constructed. In a second experiment, several features of the phase-delaying effects of $\mathrm{GRP}_{1-27}$ were assessed: (1) A dose-response curve was generated for the phase-delaying effects of $\mathrm{GRP}_{1-27}$ by injecting $1 \mu \mathrm{l}$ of saline containing $0,5.22,16.7,50$, or 150 pmol doses of $\mathrm{GRP}_{t-27}$ early in the subjective night [circadian time (CT) 12-14, with CT12 defined as activity onset]. (2) The influence of injection volume was examined by administering $\mathrm{GRP}_{1-27}(50 \mathrm{pmol})$ in vehicle volumes of $0.06,0.125,0.25,0.5$, or $1.0 \mu \mathrm{l}$ early in the subjective night (CT12-14). (3) The specificity of the pharmacological effects of GRP ${ }_{1-27}$ at CT12-14 was assessed by injecting either the BN/GRPpreferring receptor antagonist BIM $26226(500 \mathrm{pmol}$ in $0.5 \mu \mathrm{l})$ or saline vehicle 10 min prior to injection of either $\operatorname{GRP}_{1-27}(50$ pinul in $0.5 \mu \mathrm{l})$ or saline vehicle during CT12-14.

Since these studies were conducted in different lighting conditions from those used by Albers et al. (1991), the effects of constant lighting conditions on $\mathrm{GRP}_{1-27}$-induced phase shifts were assessed in a third experiment. We compared the effects of $\mathrm{GRP}_{1-27}$ microinjections in RR in the first study to the effects of similar treatments on animals housed in LL, to allow comparison to the study by Albers et al. (1991). In addition, in order to ensure that any effects observed were not the result of interactions of the drug with the very dim red light or the bright white light, we repeated the study using hamsters housed in total darkness (DD). Animals in LL were injected with $0.5 \mu \mathrm{l}$ saline, either alone or containing 50 or $150 \mathrm{pmol}$ of $\mathrm{GRP}_{1-27}$ at CT4-8, CT12-14, or CT2024. Animals in DD were tested with saline or $150 \mathrm{pmol}$ of $\mathrm{GRP}_{1-27}$ in $0.5 \mu$ l saline at CT12-14 or CT20-24 only, since these were the phases at which the largest shifts were induced. Injections of animals in RR and DD were performed with the aid of a head-mounted infrared source and viewer (FJW Industries, Mt. Prospect, IL).

In the fourth experiment, we examined the proposition that $\mathrm{GRP}_{\mathrm{t}-27}$, PHI, and VIP interact synergistically to exert a maximal effect on the hamster circadian pacemaker. We tested this hypothesis by studying the phase-shifting effects on rhythms of microinjections of $\mathrm{GRP}_{1-27}$, PHI, and VIP, administered alone or in a ncuropeptide cocktail. As in the single-peptide studies, one group of animals was tested in DD while another group was tested in LL to allow a direct comparison with the Albers et al. (1991) study. Animals were injected with one of the peptides (50 or $150 \mathrm{pmol}$ dissolved in $0.5 \mu \mathrm{l}$ saline), an equimolar neuropeptide cocktail containing $50 \mathrm{pmol}$ of each neuropeptide, or vehicle alone at CT12-14 or 20-24. Injections of animals in DD were performed with the aid of the infrared viewer.

Analysis of phase shifts. Phase shifts were assessed using the line of best fit method (Daan and Pittendrigh, 1976). Briefly, activity was recorded as raster displays generated both from event recorders and a computerized data acquisition system. A line was fitted visually along the activity onsets (=CT12) for 7-10 d prior to an injection and extrapolated to predict the onset of activity on the day following an injection. Discounting 2-3 d of transient cycles, a line was then fitted through the activity onsets for $7-10 \mathrm{~d}$ of stable rhythmicity following 
the injection, and extrapolated back to the day following the injection. The horizontal difference between the predicted onsets was measured and converted to yield the phase shift in minutes. Phase shifts were rated independently by two experienced observers (one blindly, with respect to treatment) and their assessments averaged. In the case of a discrepancy $>10$ min between the observers' ratings, the phase shift was rated a second time by both observers and a consensus reached. The observers' assessments were compared using a subset of the data, and the correlation between their ratings was 0.93 . If activity onsets were highly irregular either before or after a treatment, the data related to that treatment were discarded.

Phase shifts were analyzed using analyses of variance followed by planned comparisons tests between individual means ( $1 \mathrm{df})$ or TukeyKramer post hoc tests, where appropriate. Significance in all cases was defined as $p<0.05$. Phase shifts were considered to be greater than 0 when the calculated $95 \%$ confidence intervals for a mean value did not overlap the 0 value. Statistical analyses were performed using SUPERANOVA on a Macintosh computer.

Histological analysis. At the conclusion of the experiment, hamsters were deeply anesthetized with an intraperitoneal injection of sodium pentobarbital, and perfused intracardially with $50 \mathrm{ml}$ of $165 \mathrm{mM} \mathrm{NaCl}$ followed by $100 \mathrm{ml}$ of $10 \%$ formalin. Brains were removed, postfixed for $48 \mathrm{hr}$, and cut on a cryostat into $40 \mu \mathrm{m}$ coronal sections. Sections were stained with Cresyl violet and examined to identify the location of the cannula tips. Tip placements were classified according to their approximate distance from the external border of the $\mathrm{SCN}$; data from animals with tips $>600 \mu \mathrm{m}$ from the external border of the SCN were excluded from further analysis.

\section{Results}

Experiment 1: phase-response curve for $G_{R P_{1-27}}$

Microinjection into the $S C N$ region of $\mathrm{GRP}_{1-27}(150 \mathrm{pmol}$ in 1 $\mu$ l) caused substantial phase-dependent phase shifts of hamster activity rhythms in RR (Figs. $1 A, 2 A$ ), whereas control injections of saline vehicle had only small effects at any CT (Figs. $1 B$, $2 A$ ). Phase-shift data were grouped into $4 \mathrm{hr}$ bins and analyzed with a two-way ANOVA. There was no main effect of drug, but there was a significant main effect of circadian time $\left(F_{5,119}=\right.$ 10.67, $p<0.0005)$ and a significant CT $\times$ drug interaction $\left(F_{5,119}=5.65, p<0.0005\right) . \mathrm{GRP}_{1-27}$ effects were phase dependent: there were no differences between the effects of saline and GRP $_{1-27}$ injections at some circadian phases, but there were significantly larger phase delays induced by $\mathrm{GRP}_{\mathrm{I}-27}$ than by saline at $\mathrm{CT} 12-16(\mathrm{df}=1, F=17.58, p<0.001)$, and significantly larger phase advances at CT20-24 (df $=1, F=8.65, p<$ 0.005 ) (Fig. 3). Examination of the $95 \%$ confidence intervals for the mean phase shifts induced in different $4 \mathrm{hr}$ intervals indicated that both saline and $\mathrm{GRP}_{1-27}$ caused phase shifts greater than 0 min at CT8-12 and 12-16, but the average saline-induced shifts were very small at these phases (delays of 14.3 and 9.3 min, respectively). GRP $_{1-27}$ also caused phase shifts greater than 0 min at CT20-24, while saline did not. To examine this phase dependence in more detail, data were grouped into $2 \mathrm{hr}$ bins. $\mathrm{GRP}_{1-27}$ caused the largest average phase delays at CT12-14 $(66.4 \pm 11.7 \mathrm{~min}$; mean \pm SEM), and the largest phase advances at CT22-24 (78.4 $\pm 33.9 \mathrm{~min})$; saline injections caused average delays of $12.5 \pm 3.5 \mathrm{~min}$ and advances of $6.8 \pm 4.5$ min at these phases.

\section{Experiment 2: $G R P_{1-27}$-induced phase delays}

Microinjection of $\mathrm{GRP}_{1-27}(5.22-150 \mathrm{pmol})$ in $1 \mu \mathrm{l}$ volumes into the $\mathrm{SCN}$ region of hamsters free running in $\mathrm{RR}$ caused phase delays in activity at CT12-14 which depended on the dose of $\operatorname{GRP}_{1-27}\left(F_{4,44}=3.783, p<0.01\right)$ (Figs. $\left.2 B, 4\right)$. Maximal phase delays were induced by the $150 \mathrm{pmol}$ dose, while the $5.22 \mathrm{pmol}$ dose induced the smallest delays. The size of delay shifts increased from those caused by saline injections (a delay of 12.5 $\pm 3.5 \mathrm{~min})$ to those caused by the highest dose of $\operatorname{GRP}_{1-27}(66.4$ $\pm 11.7 \mathrm{~min}$ ). Phase delays which were significantly larger than those caused by saline were induced by the $16.7 \mathrm{pmol}(\mathrm{df}=1$, $F=8.654, p<0.01), 50 \mathrm{pmol}(\mathrm{df}=1, F=5.073, p<0.05)$, and $150 \mathrm{pmol}(\mathrm{df}=1, F=12.514, p<0.005)$ doses of $\mathrm{GRP}_{1-27}$, but not by the lowest dose $(5.22 \mathrm{pmol})$.

$\mathrm{GRP}_{1-27}(50 \mathrm{pmol})$ in volumes of $0.06-1.0 \mu \mathrm{l}$ phase delaycd hamster activity rhythms when injected at CT12-14. The results of a one-way ANOVA indicated that injection volume had no significant effect on $\mathrm{GRP}_{1-27}$-induced phase delays $\left(F_{4,29}=0.51\right.$, $p>0.05)$. The magnitude of the mean delay shifts varied from a minimum of $39.7 \pm 10.4 \mathrm{~min}$ at the $0.25 \mu \mathrm{l}$ volume to a maximum of $60.3 \pm 13.1 \mathrm{~min}$ at the $0.06 \mu \mathrm{l}$ volume, but no significant differences were found when individual means were compared post hoc with the Tukey-Kramer test $(p>0.05$ for all comparisons).

A one-way ANOVA was used to assess the effects of pretreatment with the BN/GRP receptor antagonist BIM 26226 or saline on phase shifts induced by subsequent injection of $\mathrm{GRP}_{1-27}$. There was a significant effect of drug treatment $\left(F_{1,26}\right.$ $=13.624, p<0.005$ ) on phase shifts induced by paired injections of saline, GRP ${ }_{1-27}$, and BIM 26226 at CT12-14. Phase delays induced by injections of saline followed by $\operatorname{GRP}_{1-27}(50$ pmol in $0.5 \mu \mathrm{l}$ ) at CT12-14 averaged $65.7 \pm 4.0 \mathrm{~min}$. These shifts were significantly attenuated when the BN/GRP-preferring receptor antagonist BIM $26226(500 \mathrm{pmol}$ in $0.5 \mu \mathrm{l})$ was given prior to the $\mathrm{GRP}_{1-27}$ injection (mean delay: $23.9 \pm 9.9 \mathrm{~min}$; $\mathrm{df}$ $=1, F=16.242, p<0.001$ ) (Figs. 5, 6). Paired injections of BIM 26226 followed by saline caused similar small phase delays $(25.3 \pm 3.9 \mathrm{~min})$, while the pairing of saline followed by saline caused very small phase delays $(13.0 \pm 6.9 \mathrm{~min})$. Planned comparisons indicated that the shifts induced by the combinations BIM 26226/GRP ${ }_{1-27}$, BIM 26226/saline, and saline/saline did not differ significantly $(p>0.05)$.

\section{Experiment 3: effects of lighting conditions}

In LL, microinjections of $\mathrm{GRP}_{\mathrm{I}-27}(50$ or $150 \mathrm{pmol}$ in $0.5 \mu \mathrm{l})$ in the $\mathrm{SCN}$ region of hamsters induced phase shifts which differed from 0 min at CT12-14 and CT20-24 but not at CT4-8 (Figs. $7,8 B$ ). A two-way ANOVA was used to compare the effects of the drug and saline injections at the three circadian phases tested. There was no significant main effect of drug, but there was a significant main effect of circadian phase $\left(F_{2,54}=30.13, p<\right.$ $0.005)$, and a significant drug $\times$ circadian phase interaction $\left(F_{3,54}\right.$ $=9.91, p<0.0005)$. $\mathrm{GRP}_{1-27}(50 \mathrm{pmol})$ induced significantly larger phase shifts at CT12-14 than did saline $(46.13 \pm 7.4 \mathrm{vs}$

Figure 1. Scatterplot of the phase-shifting effects of microinjections into the SCN at various times in the circadian cycle. $A$, Effects of GRP ${ }_{\mathrm{I}-27}$ $(150 \mathrm{pmol}$ in $1 \mu \mathrm{l})$ and $B$, effects of saline vehicle $(1 \mu \mathrm{l})$ injected into the SCN region of hamsters free running in constant dim red light. Each point represents the phase shift (in min) resulting from a single injection. Phase advances are shown as positive values and phase delays as negative values. 


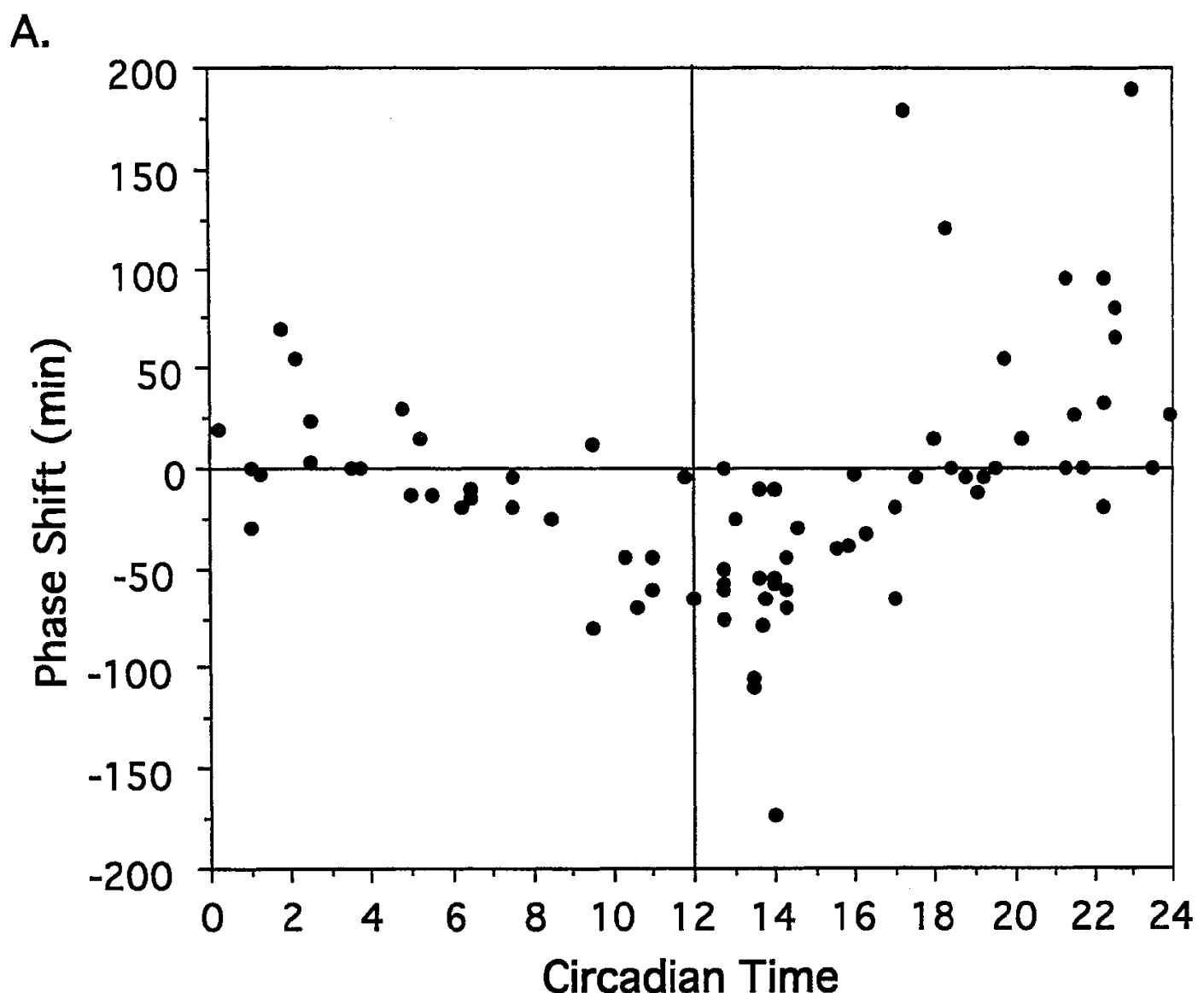

B.

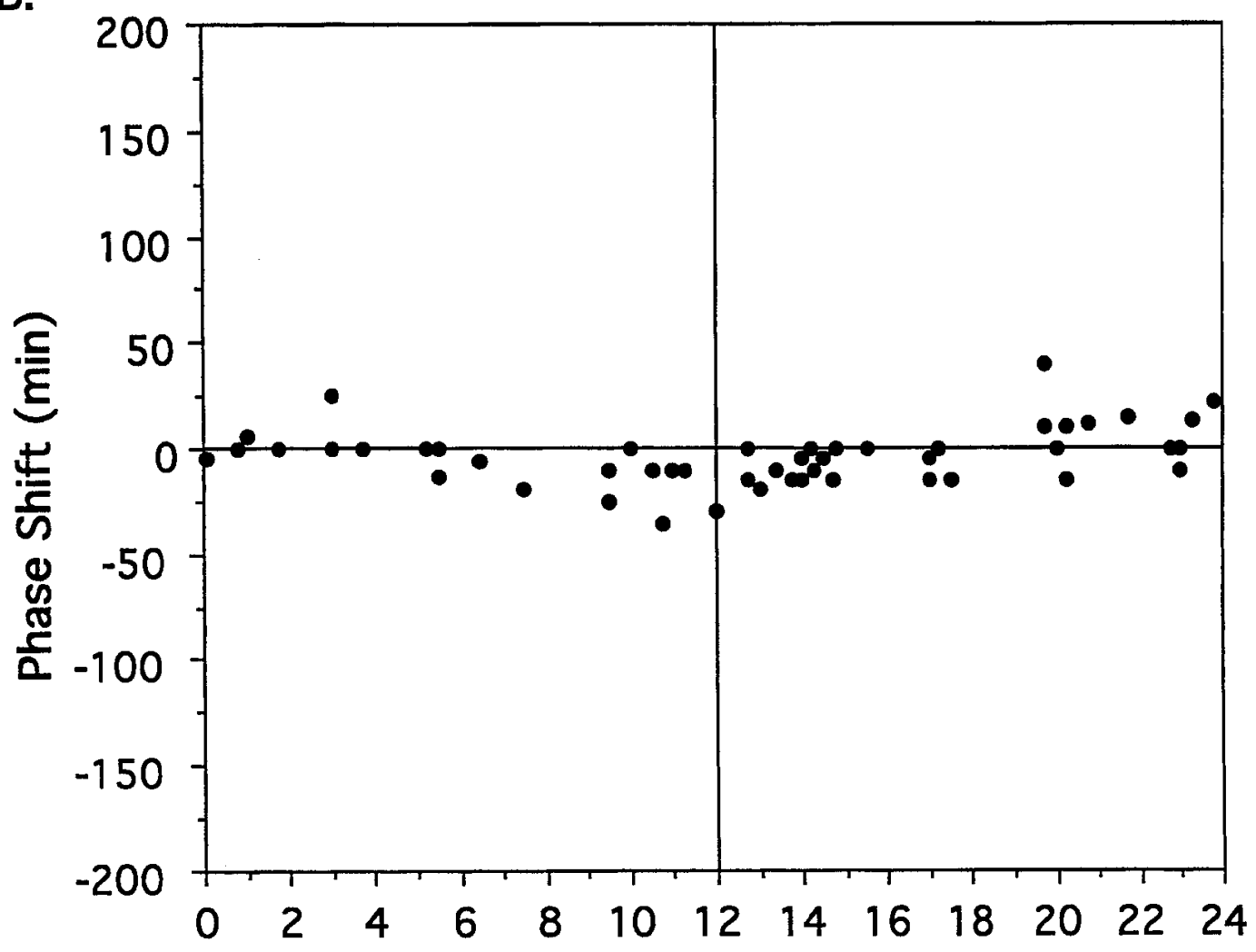

Circadian Time 


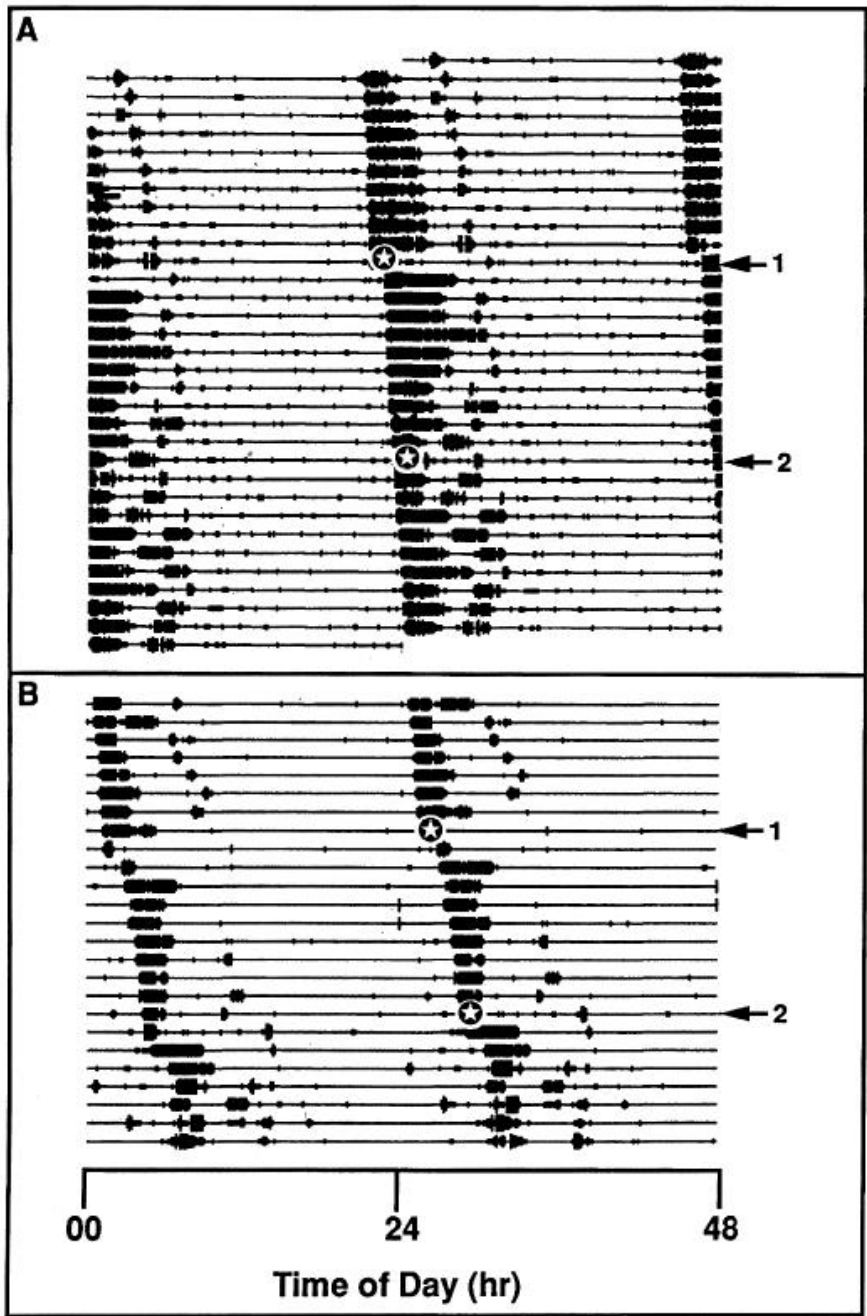

Figure 2. Double-plotted wheel-running activity records of hamsters housed in constant dim red light. $A$, Phase-shifting effects of $\mathrm{GRP}_{1-27}$ $(150 \mathrm{pmol})(\leftarrow I)$ or saline $(\leftarrow 2)$ microinjected into the $\mathrm{SCN}$ region at CT12-14 $(\star)$. B. Phase-shifting effects of GRP $_{1-27} 50 \mathrm{pmol}(\leftarrow l)$ or $16.7 \mathrm{pmol}(\leftarrow 2)$ microinjected into the SCN region at CT12-14 $(\star)$.

$10.5 \pm 6.1$ min delays; $\mathrm{df}=1, F=7.29, p<0.01$ ), and larger phase advances at CT20-24 $(31.38 \pm 11.3$ min advance vs a $7.6 \pm 6.6$ min delay for saline; $\mathrm{df}=1, F=10.58, p<0.005)$. Similarly, $\mathrm{GRP}_{1-27}$ at the high dose $(150 \mathrm{pmol})$ induced significantly larger phase delays $(57.6 \pm 14.14 \mathrm{~min})$ than saline at CT12-14 (df $=1, F=11.84, p<0.005$ ), and significantly larger phase advances $(35.0 \pm 10.75 \mathrm{~min})$ at CT20-24 $(\mathrm{df}=1$, $F=13.47, p<0.001)$.

Hamsters were also tested in DD for the effects on phase of microinjections of $\mathrm{GRP}_{1-27}(150 \mathrm{pmol}$ in $0.5 \mu \mathrm{l})$ into the $\mathrm{SCN}$ region (Fig. 8A). A two-way ANOVA on phase shifts induced by saline or $\mathrm{GRP}_{1-27}$ at two circadian phases indicated significant main effects of drug $\left(F_{1,23}=10.43, p<0.005\right)$ and circadian phase $\left(F_{1.23}=178, p<0.0005\right)$, and a significant drug $\times$ circadian phase interaction $\left(F_{1.23}=135, p<0.0005\right)$. $\mathrm{GRP}_{1-27}$ induced significantly larger phase delays than did saline at CT12$14(72.9 \pm 5.8$ vs $1.6 \pm 3.9 \mathrm{~min} ; \mathrm{df}=1, F=123.86, p<$ 0.0005 ), and significantly larger phase advances at CT20-24 $(47.0 \pm 5.0$ vs $6.7 \pm 2.8 \mathrm{~min} ; \mathrm{df}=1, F=31.79, p<0.0005)$.

The mean phase shifts induced by $\mathrm{GRP}_{1-27}$ at two circadian

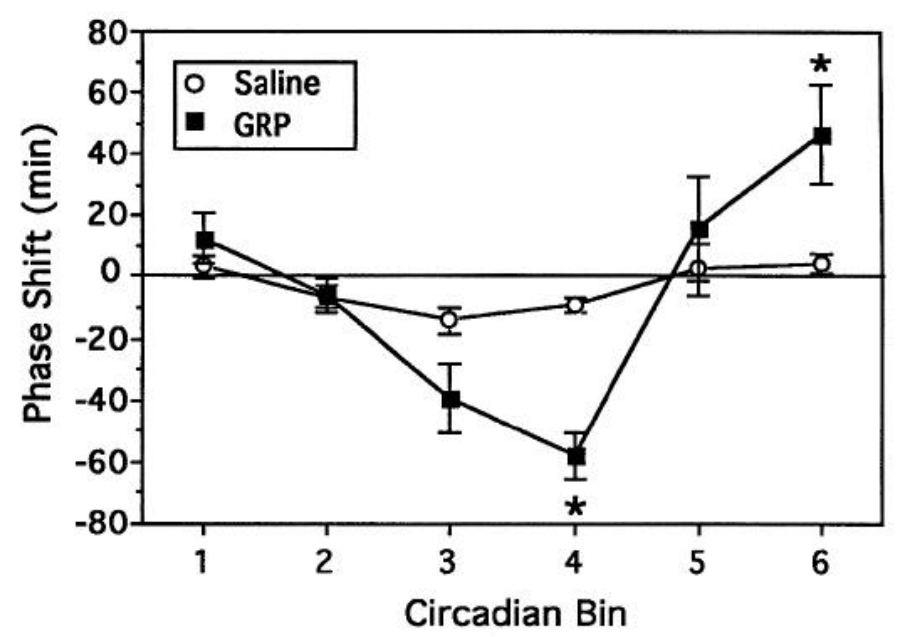

Figure 3. Phase-shifting effects of microinjections of $\mathrm{GRP}_{1-27}(150$ pmol in $1 \mu \mathrm{l} ;-)$ or saline $(1 \mu \mathrm{l} ; \bigcirc)$ into the SCN region of hamsters free running in constant dim red light. Each point represents the mean \pm SEM phase shift (in min) in that $4 \mathrm{hr}$ CT bin. *, significantly different from the phase-shifting effects of saline vehicle in that $4 \mathrm{hr}$ CT bin ( $p$ $<0.05$ ). Phase advances are shown as positive values and phase delays as negative values.

phases (CT12-14 and CT20-24) were compared across the three lighting conditions (RR, LL, and DD) using a two-way ANOVA. There was no significant main effect of lighting condition nor any significant interaction of lighting conditions with phase $\left(F_{2.51}=0.27, p>0.05\right)$; the direction and amplitude of the shifts induced by $\mathrm{GRP}_{1-27}$ at these phases were independent of lighting condition.

Experiment 4: effects of coadministration of $G R P_{1-27}, P H I$, and VIP

A three-way analysis of variance was used to evaluate the phase shifts evoked by the $150 \mathrm{pmol}$ doses of GRP, PHI, and VIP alone as well as the equimolar peptide cocktail at CT12-14 and CT2024 under LL or DD. The overall peptide $\times$ time $\times$ constant lighting condition interaction was not significant $\left(F_{4,137}=0.149\right.$, $p>0.05)$, but the peptide $\times$ time interaction was highly significant $\left(F_{4,137}=9.35, p<0.0005\right)$, as was the main effect of

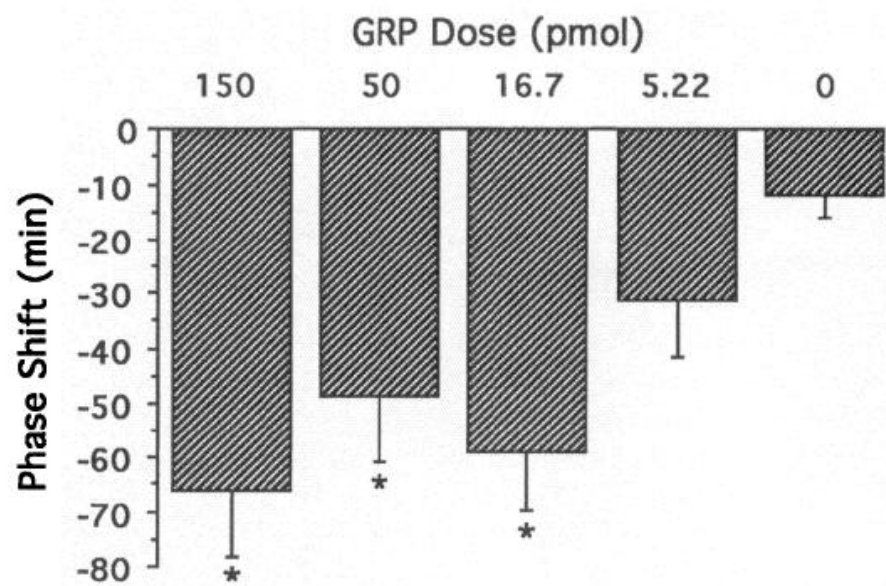

Figure 4. Dose dependence of $\mathrm{GRP}_{1-27}$-induced phase shifts at CT1214. Each bar represents the mean phase shift (in min \pm SEM) for the dose shown. *, significantly different from phase-shifting effects of control (saline) injection $(p<0.05)$. 


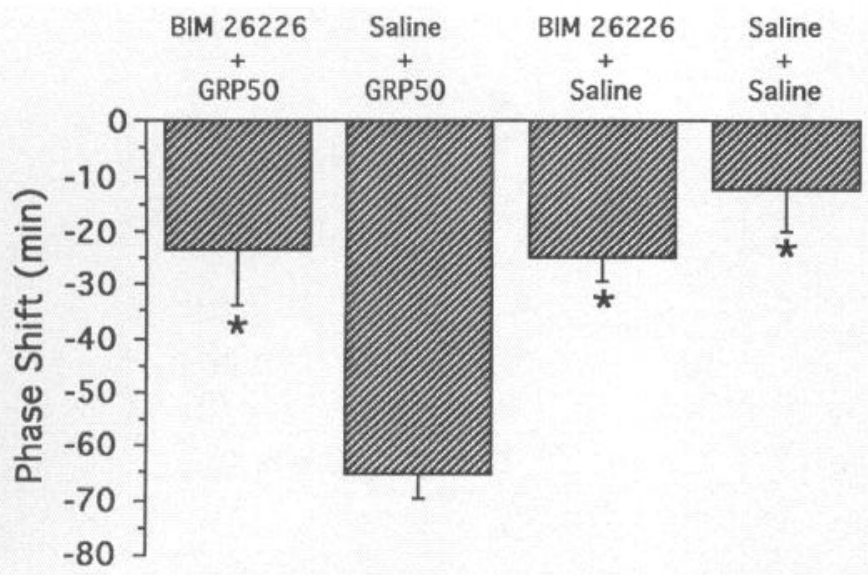

Figure 5. Effects of BIM 26226 on phase-shifting effects of $\mathrm{GRP}_{1-27}$ (50 pmol) microinjected at CT12-14. Each bar represents mean phase shift (in min \pm SEM) for that treatment. *, significantly different from phase-shifting effects of the saline/GRP ${ }_{1-27}$ injection sequence $(p<$ $0.05)$.

time $\left(F_{1,137}=133.1, p<0.0005\right)$. The peptide $\times$ constant lighting condition interaction, time $\times$ constant lighting condition interaction, and main effects of peptide and constant lighting condition were all nonsignificant $(p>0.05)$. The phase shift data were subsequently collapsed across constant lighting conditions, and mean phase shifts compared using planned single degree of freedom tests (Fig. 9). At CT12-14, 150 pmol GRP ${ }_{1-27}$ evoked the largest average phase delay $(60.5 \pm 10.3 \mathrm{~min})$, which was significantly larger than the phase delay due to vehicle $(4.5 \pm$ $2.6 \mathrm{~min})(\mathrm{df}=1, F=24.4, p<0.0005)$ or PHI $(150 \mathrm{pmol}$; $34.5 \pm 8.5 \mathrm{~min})(\mathrm{df}=1, F=5.16, p<0.05)$. PHI evoked a significantly larger phase delay than vehicle ( $\mathrm{df}=1, F=5.3$, $p<0.05)$, as did $150 \mathrm{pmol}$ VIP $(33.9 \pm 6.2 \mathrm{~min}$; $\mathrm{df}=1, F=$ $5.4, p<0.05)$. The equimolar peptide cocktail evoked a large phase delay $(50.9 \pm 10.0 \mathrm{~min})$ which was significantly larger than the delay due to vehicle ( $\mathrm{df}=1, F=14.6, p<0.0005$ ). No other significant differences were detected using single degree of freedom comparisons.

At CT20-24, VIP evoked a moderate phase advance (42.2 \pm $11.8 \mathrm{~min}$ ) which was significantly larger than the phase advance induced by vehicle $(2.0 \pm 4.5 \mathrm{~min})(\mathrm{df}=1, F=10.1, p<$ $0.005)$ or PHI $(10.2 \pm 5.3 \mathrm{~min})(\mathrm{df}=1, F=5.6, p<0.05)$. The equimolar cocktail induced a moderate phase advance (38.1 $\pm 8.4 \mathrm{~min}$ ) which was significantly larger than the phase advance induced by vehicle ( $\mathrm{df}=1, F=10.6, p<0.005)$ or PHI (df $=1, F=5.5, p<0.05$ ). GRP evoked a moderate phase advance $(33.3 \pm 4.9)$ which was significantly larger than the phase advance to vehicle ( $\mathrm{df}=1, F=6.9, p<0.01)$. No other significant differences were detected using single degree of freedom comparisons.

Under DD only, some animals were also injected with 50 pmol doses of $\mathrm{GRP}_{1-27}, \mathrm{PHI}$, and VIP as well as the equimolar (150 pmol) peptide cocktail at CT12-14. One-way analysis of variance indicated a significant effect of drug type on phase shifts $\left(F_{4,34}=5.58, p<0.005\right)$. The equimolar $(150$ pmol $)$ cocktail evoked the largest phase delay $(59.3 \pm 13.0 \mathrm{~min})$, which was significantly larger than phase delays evoked by $50 \mathrm{pmol}$ PHI $(20.7 \pm 8.3 \mathrm{~min})(\mathrm{df}=1, F=6.7, p<0.05), 50 \mathrm{pmol}$ VIP $(18.3 \pm 7.1 \mathrm{~min})(\mathrm{df}=1, F=8.3, p<0.01)$, or saline $(1.2 \pm 3.0 \mathrm{~min})(\mathrm{df}=1, F=19.2, p<0.0005) . \mathrm{GRP}_{1-27}(50$ pmol) evoked a moderate phase delay $(42.4 \pm 13.9 \mathrm{~min})$ that

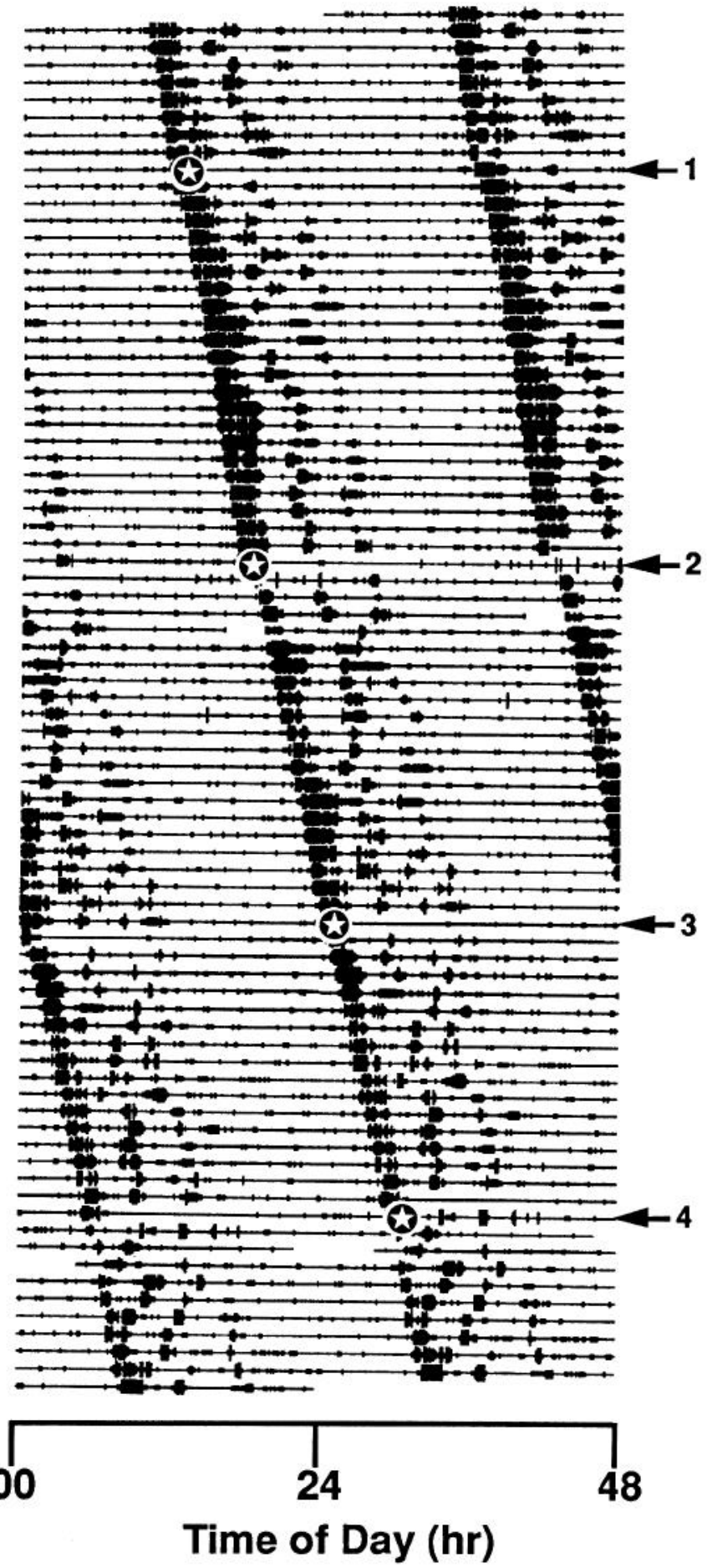

Figure 6. Double-plotted wheel-running activity records of a hamster free running in constant dim red light. Phase-shifting effects of the following sequences of microinjections at CT12-14 are shown: BIM $26226(500 \mathrm{pmol}) / \mathrm{GRP}_{1-27}(50 \mathrm{pmol})(\leftarrow 1)$, saline/GRP $\mathrm{I}_{-27}(\leftarrow 2)$, BIM 26226/saline $(\leftarrow 3)$, or saline/saline $(\leftarrow 4)$.

was significantly larger than the phase delay due to injection of saline vehicle $(\mathrm{df}=1, F=8.0, p<0.01)$. The phase shift evoked by microinjections of the peptide cocktail $(150 \mathrm{pmol})$ did not differ significantly from the phase delay induced by $\mathrm{GRP}_{1-27}(50$ pmol: $p>0.05)$, and no other significant differences 


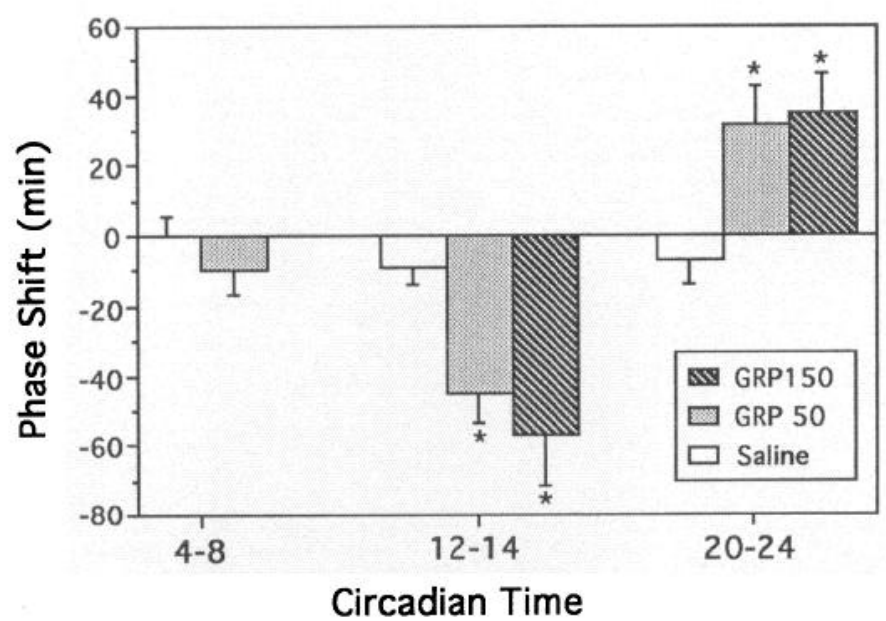

Figure 7. Phase-shifting effects of $\mathrm{GRP}_{1-27}(50$ or $150 \mathrm{pmol}$ in $0.5 \mu \mathrm{l})$ or saline $(0.5 \mu 1)$ on hamsters free running in constant light conditions. Each bar represents the mean \pm SEM phase shift (in min) in that circadian interval. *, significantly different from phase-shifting effects of control (saline) injections in the same interval $(p<0.05)$. Phase advances are shown as positive values and phase delays as negative values.

between treatments were found using single degree of freedom comparisons.

\section{Discussion}

These results do not support the contention that the apparently colocalized neuropeptides, $\mathrm{GRP}_{1-27}, \mathrm{PHI}$, and VIP, must function collectively in order to exert maximal effects on the circadian pacemaker in the hamster SCN. These data are also inconsistent with the suggestion that these neuropeptides individually have little effect on SCN activity; rather, they clearly demonstrate that each neuropeptide can phase shift the circadian pacemaker. $\mathrm{GRP}_{1-27}$ is the most potent phase-delaying agent and has moderate phase-advancing potency; VIP is a modest phase-delaying and an effective phase-advancing agent; and PHI is a moderate phase-delaying agent only, while vehicle had few effects at any point of the circadian cycle. Coinjection of PHI, VIP, and GRP I27 $_{12}$ to a total of $150 \mathrm{pmol}$ gave no evidence of synergism. Instead, the 150 pmol cocktail caused phase shifts that were marginally smaller than those induced by $150 \mathrm{pmol}$ of $\mathrm{GRP}_{127}$ alone, and considerably smaller than even a simple addition of the effects of the constituent 50 pmol peptide doses would predict.

$\operatorname{GRP}_{1-27}(150 \mathrm{pmol})$ induced significant phase shifts when microinjected into the $\mathrm{SCN}$ of free-running hamsters in the early and late subjective night. When collapsed across lighting conditions in experiments $1-3$, phase delays at CT12-14 averaged $66 \mathrm{~min}$ and phase advances at CT20-24 averaged $43 \mathrm{~min}$, while delays and advances averaged $61 \mathrm{~min}$ and $33 \mathrm{~min}$, respectively, at these phases in the fourth experiment. The magnitudes of these average phase shifts were unaffected by constant lighting conditions, indicating that these lighting regimes do not alter the sensitivity of hamster $\mathrm{SCN}$ cells to $\mathrm{GRP}_{1-27}$. GRP ${ }_{1-27}$-induced phase delays were unaffected by injection volume and showed a degree of dose relatedness. Most importantly, phase delays induced by 50 pmol $\mathrm{GRP}_{1-27}$ were attenuated by pretreatment with BIM 26226, indicating that these effects were apparently mediated via the GRP-preferring receptor subtype.

These results are consistent with data from neurophysiological studies which indicated that $\mathrm{GRP}_{1-27}$ and GRP analogs potently

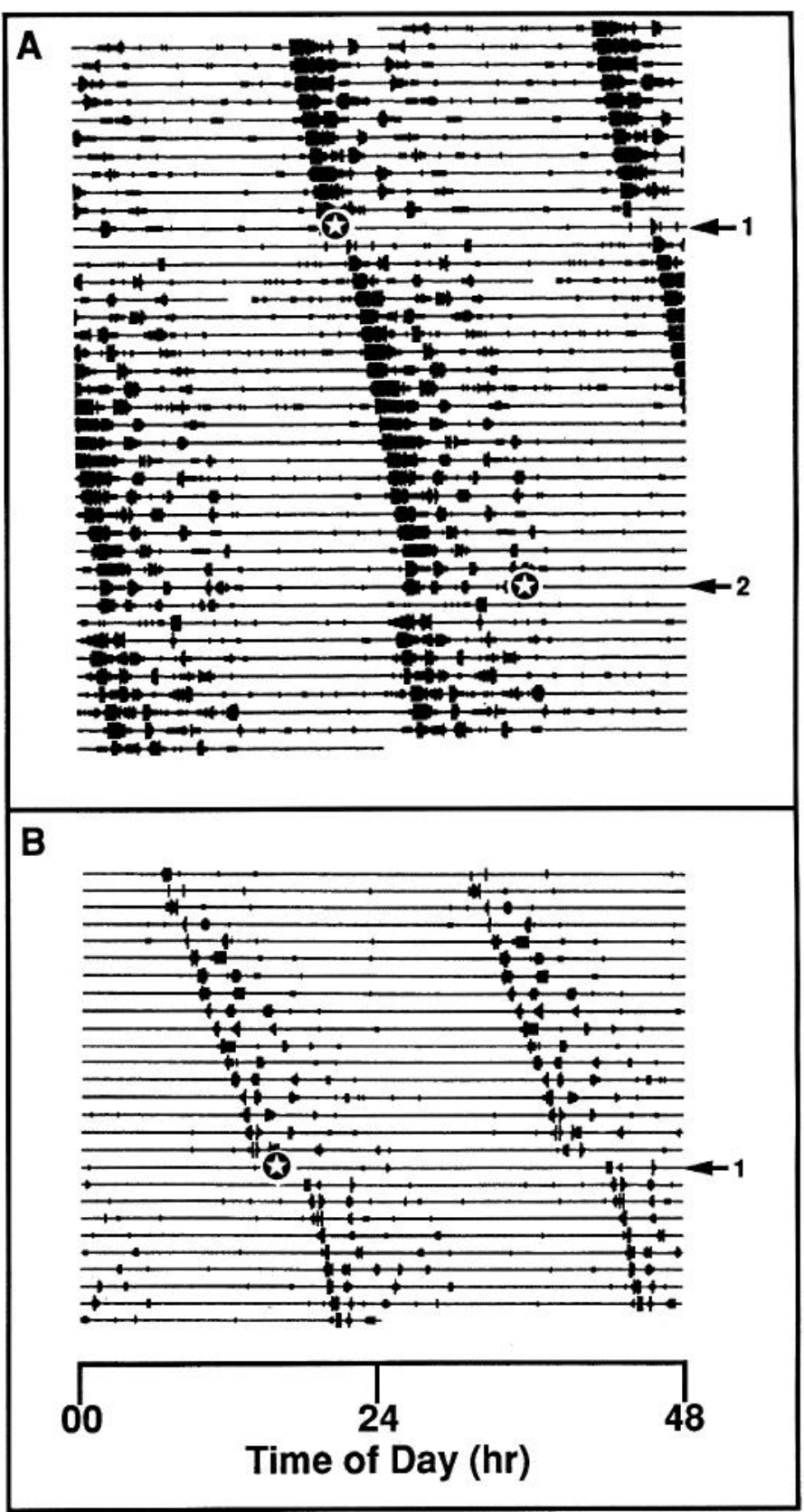

Figure 8. Double-plotted wheel-running activity records of hamsters free running in constant dark conditions $(A)$ or constant light conditions (B). A, Phase-shifting effects of $\mathrm{GRP}_{1-27}(150 \mathrm{pmol}$ in $0.5 \mu \mathrm{l})$ microinjected at CT12-14 $(\leftarrow 1)$ or CT20-24 $(\leftarrow 2)$. B. Phase-shifting effects of $\mathrm{GRP}_{1-27}(150 \mathrm{pmol}$ in $0.5 \mu \mathrm{l})$ microinjected at CT12-14 $(\leftarrow 1)$.

activated rodent SCN cells in vitro (Piggins and Rusak, 1993a; Tang and Pan, 1993; Pinnock et al., 1994), and that these neurophysiological effects were also blocked by the GRP-preferring receptor antagonist BIM 26226 (Piggins et al., 1994b). In addition, the phase of the circadian cycle at which $\mathrm{GRP}_{1-27}$ delays the circadian pacemaker in vivo corresponds to the phase of the projected circadian cycle at which a larger percentage of hamster SCN cells in vitro are responsive to GRP analogs (Piggins et al., 1994b). Since these effects are apparently mediated by the GRP-preferring receptor subtype, these data may suggest that increased numbers of this receptor are available in the SCN at 

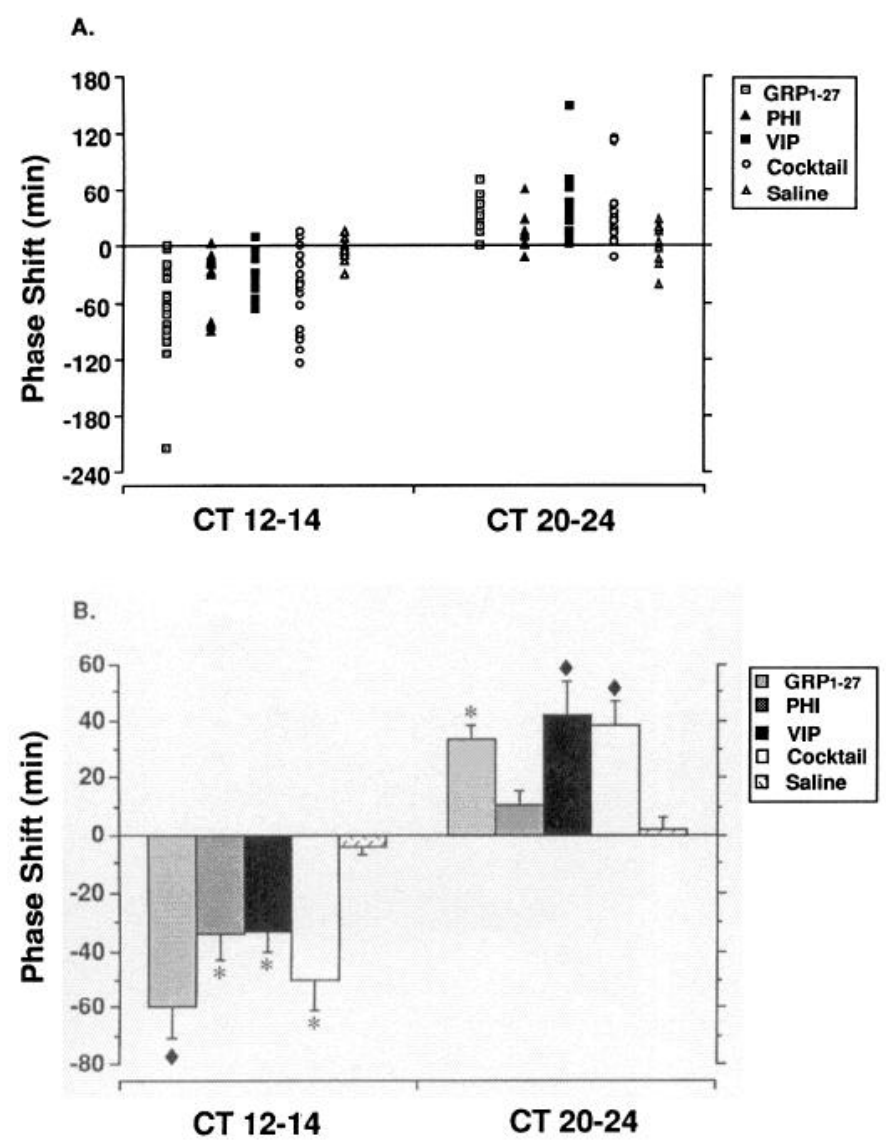

Figure 9. Phase-shifting effects of $\mathrm{GRP}_{1-27}$, PHI, or VIP (150 pmol) microinjected at CT12-14 or 20-24 on hamsters in constant conditions. $A$, Each point represents the phase shift of one animal. B, Each bar represents the mean phase shift (in min \pm SEM; $n=12-22$ per mean) in that circadian interval. *, significantly different from the phase-shifting effects of saline at that phase $(p<0.05) ; \diamond$, significantly different from the phase-shifting effects of both saline and PHI at that phase ( $p$ $<0.05$ ). Phase advances are shown as positive values and phase delays as negative values.

CT12-16. Overall, these results indicate that $\mathrm{GRP}_{1-27}$ potently and robustly resets the circadian pacemaker with a temporal pattern similar to that of light, apparently by its interaction with the BN/GRP-preferring receptor subtype.

VIP (150 pmol) induced moderate phase delays at CT12-14 (34 $\mathrm{min})$ and moderate phase advances at CT20-24 (42 min). PHI (150 pmol) evoked moderate phase delays at CT12-14 (35 min) but only small phase advances at CT20-24 (10 min). At CT20-24, VIP (150 pmol) was a more potent phase-advancing drug than PHI. Phase shifts evoked by PHI and VIP were independent of the constant lighting conditions, suggesting that ambient illumination does not alter sensitivity of the hamster SCN to these peptides. The influence of VIP and PHI on hamster SCN neuronal activity has not been examined extensively, but the data of Albers et al. (1991) indicate that both peptides can increase SCN cell firing rates.

The mechanism mediating the effects of these peptides on the hamster SCN is unknown. High grain densities of ${ }^{125}$ I-VIP binding sites are present in the rat and hamster SCN (Dietl et al., 1990; Robinson and Fuchs, 1993; Hill et al., 1994), and recent in situ hybridization results show intense expression of mRNA for the $\mathrm{VIP}_{2}$ receptor in the rat SCN (Usdin et al., 1994). Since PHI has less affinity than VIP for VIP receptors (Cauvin et al.,
1990; Huang and Rorstad, 1990; Usdin et al., 1994), a change in receptor affinity state during the night may account for the difference in the phase-advancing potencies of these peptides at CT20-24 despite their very similar effects at CT12-14. Overall, these data indicate that PHI and VIP phase shift the hamster circadian pacemaker through an as yet uncharacterized mechanism.

The equimolar neuropeptide cocktail (150 pmol) phase shifted hamster locomotor activity rhythms in the same direction as did 150 pmol injections of $\mathrm{GRP}_{1-27}$, PHI, and VIP when administered individually. When the data from the fourth experiment were collapsed across constant lighting conditions, the apparent rank order of phase-delaying potency at CT12-14 was $\mathrm{GRP}_{1-27}$ $(61 \mathrm{~min})=\operatorname{cocktail}(51 \mathrm{~min})>\mathrm{PHI}(35 \mathrm{~min})=\mathrm{VIP}(34 \mathrm{~min})$ $>$ saline (4.5 min). At CT20-24, the apparent rank order of phase-advancing potency was VIP $(42 \mathrm{~min})=\operatorname{cocktail}(38 \mathrm{~min})$ $=\mathrm{GRP}_{1-27}(33 \mathrm{~min})>\mathrm{PHI}(10 \mathrm{~min})=$ saline $(2.0 \mathrm{~min})$. The phase shifts induced by the equimolar neuropeptide cocktail were not significantly greater than those to GRP $_{1-27}$ or VIP, but were larger than PHI alone at CT12-14 and CT20-24. When tested in DD, phase delays induced by the cocktail at CT12-14 were less than the summed effects of individually administered 50 pmol doses of $\mathrm{GRP}_{1-27}+\mathrm{PHI}+\mathrm{VIP}$ (58 vs $82 \mathrm{~min}$, respectively), and not significantly greater than the phase delay to $\mathrm{GRP}_{1-27}(50 \mathrm{pmol})$ alone $(42 \mathrm{~min})$. Since the phase-shifting effect of the cocktail was less than the summed effects of the 50 pmol doses of the peptides, these data indicate a lack of synergism among the effects of these peptides. Further, because $\operatorname{GRP}_{1-27}(150 \mathrm{pmol})$ evoked shifts similar in magnitude to those of the cocktail, the data do not support the hypothesis that these apparently colocalized neuropeptides must interact to exert maximal effects on the circadian pacemaker.

These results generally contrast with those of a previous study in which $\mathrm{GRP}_{1-27}, \mathrm{PHI}$, and VIP individually induced only small to moderate phase delays, whereas an equimolar cocktail evoked very large delays in the activity rhythms of hamsters free running in constant bright light (Albers et al., 1991). These discrepancies are difficult to resolve. The data from the $\mathrm{GRP}_{1-27}$ studies indicate that injection volume is probably not a critical variable, and the volume used in most of our experiments $(0.5$ $\mu \mathrm{l}$ ) is comparable to the $0.4 \mu \mathrm{l}$ used previously (Albers et al., 1991). Other methodological differences include the gauge of cannula used and stereotaxic coordinates for implantation, which might affect the amount of peptide that penetrates to the SCN.

If our method caused larger amounts of peptides to reach the SCN, one might expect consistently larger shifts in this study. Although we found much larger shifts to GRP than were reported by Albers et al. (1991), both reports describe comparable delay shifts to PHI and comparable advance shifts to the peptide cocktail using the same nominal doses. This makes it unlikely that differences in methods caused consistently different amounts of peptide to reach the SCN. In addition, we saw little change in shift amplitude in response to GRP doses ranging from 16.7 to $150 \mathrm{pmol}$, so even a 10-fold reduction in peptide delivery to the target using a nominal $150 \mathrm{pmol}$ dose should not have greatly reduced the amplitude of phase shifts.

An alternative explanation is that the smaller sample sizes studied by Albers et al. (1991) produced average results that do not adequately reflect the population means for these treatments. The claim that $\mathrm{GRP}_{1-27}$ alone does not produce substantial shifts in the early subjective night $(<30 \mathrm{~min})$ was based on a sample of nine injections (Albers et al., 1991). Injections at this time 
yielded consistent effects in all of our studies, and our mean of about $64 \mathrm{~min}$ reflects results from 51 animals. The claims that the peptide cocktail does not cause substantial phase advance shifts and that the cocktail has larger delaying effects than any single peptide were assessed in Albers et al. (1991) using group sizes of 7-11 animals and no vehicle control injections. In our fourth experiment, we used 12-22 injections for each condition and compared our results to those of vehicle-treated controls. We observed considerable variability in phase shifts to single peptides even with these larger sample sizes (e.g., GRP $_{1-27}(150$ pmol) at Cl'12-14 induced a mean phase delay of approximately $61 \mathrm{~min}$, with a range of $0-215 \mathrm{~min} ; n=22$ ). Given this degree of variability with a only a single peptide, and the additional complications of coinjecting three peptides, a large sample size may be critical to obtaining reliable results.

In both the rat and hamster SCN, cell bodies containing PHI/ VIP and GRP $_{1-27}$ are found in areas which are innervated by the RHT. Electron microscopic studies indicate that at least VIPcontaining cells are contacted by retinal afferent terminals (Okamura et al., 1987; Ibata et al., 1989). Light induces innediateearly gene expression in $\mathrm{GRP}_{1-27^{-}}$and PHI/VIP-containing rat SCN cells at the same phases of the circadian cycle at which it can phase shift the circadian pacemaker (Earnest et al., 1993; Mikkelsen et al., 1994). These results imply that the effects of light on the retina are conveyed directly to these peptidergic cells in the rodent SCN, and that the local release of these neuropeptides might be involved at some level of the photic entrainment mechanism. Our results support this interpretation: when administcrcd alone or in combination, GRP ${ }_{1-27}, \mathrm{PHI}$, and VIP phase shift circadian rhythms at the same phases and in the same direction as do light pulses (Daan and Pittendrigh, 1976; Takahashi et al., 1984). These neuropeptides may play a role in photic entrainment, but the nature of this putative involvement will require further study.

$\mathrm{GRP}_{1-27}$ and VIP levels in the rat SCN do not show circadian fluctuations in constant conditions but are differentially affected by light. $\mathrm{GRP}_{\mathrm{t}-27}$ levels in the rat $\mathrm{SCN}$ are increased by light while VIP levels are decreased (Shinohara et al., 1992). When maintained under a 12:12 LD cycle mRNA levels for these peptides also show diurnal variation, with $\mathrm{GRP}_{1-27}$ mRNA being high early in the day and low at night, while mRNA for VIP is high at night and low during the day (Zoeller et al., 1991). These data indicate that light differentially affects $\mathrm{GRP}_{1-27}$ and VIP levels in the rat SCN. Since PHI and VIP are products of the same precursor and are probably colocalized throughout most of the rodent SCN, it seems likely that PHI levels are altered by light in a similar way. Immunocytochemical research has shown GRP $_{1-27}$ and PHI to be colocalized in some cells of the rat SCN (Okamura et al., 1986). Together, these observations imply that fluctuations in GRP ${ }_{1-27}$ and VIP (and presumably PHI) levels in axon terminals can give rise to different ratios of presynaptic release of these neuropeptides, resulting in different postsynaptic effects.

Albers et al. (1991) proposed that the larger the ratio of release of $\mathrm{GRP}_{1-27}$ to PHI/VIP early in the subjective night, the greater the phase delay induced, while the larger the ratio of release of $\mathrm{PHI} / \mathrm{VIP}$ to $\mathrm{GRP}_{1-27}$ in the late subjective night, the greater the phase advance (see Peters et al., 1994). While our results suggest that $\mathrm{GRP}_{1-27}$ is the most potent phase-delaying agent among these peptides, they are otherwise inconsistent with this model. The magnitude of the phase delay evoked by $\mathrm{GRP}_{\mathrm{I}-27}(150 \mathrm{pmol})$ alone at CT12-14 is very similar to that caused by the equimolar cocktail, while the dosage ratios of $\mathrm{GRP}_{1-27}: \mathrm{PHI} / \mathrm{VIP}$ are radically different in the two conditions. Furthermore, the magnitude of the phase advance induced by VIP (150 pmol) alone at CT20-24 is very similar to that of the equimolar cocktail at this circadian phase despite the radically different peptide ratios involved. These results demonstrate that an interaction among these neuropeptides is not a significant factor determining their phase-shifting efficacy. Further experimentation will be required to explore the possible interactions of these peptides, but the present data suggest redundancy in peptidergic mechanisms putatively involved in phase shifting the circadian pacemaker.

Other results also call into question the potential for functional interactions among $\mathrm{GRP}_{1-27}$, PHI, and VIP in the regulation of the mammalian circadian pacemaker. Anatomically, the extent of $\mathrm{GRP}_{1-27} / \mathrm{PHI}$ colocalization in the rat $\mathrm{SCN}$ has been estimated to be modest. Many $\mathrm{GRP}_{1-27}$-ir perikarya are located more laterally than PHI/VIP-ir cell bodies in the rat SCN, and GRP ${ }_{1-27^{-}}$ ir and VIP-ir fibers project in different patterns (Okamura et al., 1986; Okamura and Ibata, 1994). In addition, even the demonstration of mRNA for both $\mathrm{GRP}_{1-27}$ and PHI/VIP in a single neuron does not necessarily imply functional co-release or even colocalization in individual axon terminals. These peptides may be processed and distributed differentially to different terminal regions of a single neuron (e.g., Okamura and lbata, 1994). In the hamster $\mathrm{SCN}, \mathrm{GRP}_{1-27}$-immunostained cell bodies overlap to a small extent with PHU/VIP immunopositive perikarya, but the overall distribution of immunostained cell bodies for these peptides is different (Piggins, Semba, and Rusak, unpublished observations), and it has yet to be established whether $\mathrm{GRP}_{1-27}$ and PHI/VIP are actually colocalized to any extent in the SCN of this species. Discussion of the effects of co-release of PHI/VIP and $\mathrm{GRP}_{1-27}$ in hamsters is premature in the absence of data indicating their colocalization.

A number of other issues require further investigation before the neurochemistry of peptides in the rodent SCN can be accurately modeled. First, precursors for $\mathrm{GRP}_{1-27}$ and PHI/VIP can be cleaved into other peptide molecules, the role of which has not been assessed and could complicate any model of interactions among the larger peptides. The presence of these fragments has been demonstrated in the rodent SCN (Mikkelsen et al., 1991; Mikkelsen and Fahrenkrug, 1994), and at least one $\left(\mathrm{GRP}_{18-27}\right)$ potently activates hamster $\mathrm{SCN}$ cells in vitro (Piggins et al., 1994). Second, implicit in the ratio model is the assumption that receptors for GRP ${ }_{1-27}$ and PHI/VIP are expressed in the same cell populations in the $\mathrm{SCN}$, but there is no conclusive evidence about the availability, distribution, or even coexpression in single SCN neurons of postsynaptic receptors for these neuropeptides. Further research is required to characterize the anatomical and temporal distribution of PHI/VIP- and GRP-preferring receptors in the rodent SCN. Third, a ratio model would have to take account of photic regulation of extra-SCN sources of these peptides which may project to the SCN. In the rat, some retinal ganglion cells synthesize message for PHI/VIP, which may be transported to the SCN (Denis et al., 1993), and others show GRP ${ }_{1-27}$-ir (McKillop et al., 1988). These results raise the possibility of complex interactions among these and other peptides in the SCN, which are unlikely to be captured by a simple ratio model.

In conclusion, microinjection of $\mathrm{GRP}_{1-27}, \mathrm{PHI}$, and VIP into the $\mathrm{SCN}$ region phase delayed hamster locomotor rhythms. $\mathrm{GRP}_{1-27}$ was the most potent phase-delaying peptide, and these 
shifts were dose related up to $16.7 \mathrm{pmol}$ (with an apparent ceiling effect at higher doses). GRP ${ }_{1-27}$-induced phase shifts were independent of both constant lighting conditions and injection volume, and apparently mediated via the GRP-preferring receptor subtype. Both GRP ${ }_{1-27}$ and VIP also phase advanced locomotor rhythms. Coadministration of all three peptides failed to shift rhythms to a greater extent than $\mathrm{GRP}_{1-27}$ or VIP alone. The magnitude of the shifts resulting from coadministration was less than the summed effects of each peptide alone, indicating that the interaction among $\mathrm{GRP}_{1-27}$, PHI, and VIP was subadditive and not synergistic. Indeed, if PHI and VIP both bind to VIP receptors (Huang and Rorstad, 1990), their coinjection is likely to generate competitive rather than synergistic effects at the receptor level. Interactions among these peptides were not necessary to produce maximal effects on the circadian pacemaker. Since $\mathrm{GRP}_{1-27}, \mathrm{PHI}$, and VIP alone or in combination shifted locomotor rhythms in the same direction and at the same phases as light does, these peptides may be involved in photic entrainment of the circadian pacemaker. If these peptides are co-released in the rodent SCN, the functional consequences of this mechanism remain unknown.

\section{References}

Alhers HE, I ion S-Y, Stopa EG, Zoeller RT (1991) Interaction of colocalized neuropeptides: functional significance in the circadian timing system. J Neurosci 11:846-851.

Battey $\mathbf{J}$, Wada E (1991) Two distinct receptor subtypes for mammalian bombesin-like peptides. Trends Neurosci 14:524-528.

Bean AJ, Zhang X, Hökfelt T (1994) Peptide secretion: what do we know? FASEB J 8:630-638.

Beinfeld MC, Korchak DM, Roth BL, O'Donohue TL (1984) The distribution and chromatographic characterization of PHI (peptide histidine isoleucine amide)-27-like peptides in the rat and porcine brain. J Neurosci 4:2681-2688.

Besson J, Sarrieau A, Vial M, Marie J-C, Rosselin G, Rostene W (1986) Characterization and autoradiographic distribution of vasoactive intestinal polypeptide binding sites in the rat central nervous system. Brain Res 398:329-336.

Card JP, Moore RY (1984) The suprachiasmatic nucleus of the golden hamster: immunohistochemical analysis of cell and fiber distribution. Neuroscience 13:415-431.

Cauvin A, Vandermeers-Piret M-C, Vandermeers A, Coussaert E, De Neef P, Robberecht P, Christophe J (1990) Rat PHI, PHI-GLY and PHV $(1-42)$ stimulate adenylate cyclase in six rat tissue and cell membranes. Peptides 11:1009-1014.

Daan S, Pittendrigh CS (1976) A functional analysis of circadian pacemakers in nocturnal rodents. II. The variability of phase response curves. J Comp Physiol 106:253-266.

Denis P, Dussaillant M, Nordmann JP, Berod A, Saraux H, Rostene W (1993) Vasoactive intestinal peptide/peptide histidine isoleucine mRNA in the eye and suprachiasmatic nucleus of normal and monocularly enucleated rats. Graefes Arch Clin Exp Ophthalmol 231: $541-545$.

Dietl MM, Hof PR, Martin J-L, Magistretti PJ, Palacios JM (1990) Autoradiographic analysis of the distribution of vasoactive intestinal polypeptide binding sites in the vertebrate central nervous system: a phylogenetic study. Brain Res 520:14-26.

Dussaillant M, Sarrieu A, Gozes 1, Berod A, Rostene W (1992) Distribution of cells expressing vasoactive intestinal peptide/peptide histidine isoleucine-amide precursor messenger RNA in the rat brain. Neuroscience 50:519-530.

Earnest DJ, DiGiorio SM, Trojanyck LA, Olschowka JA (1993) Light induces expression of fos-related proteins within gastrin-releasing peptide neurons in the rat suprachiasmatic nucleus. Brain Res 627: 205-209.

Gundlach AL, Knobe KE (1992) Preprogastrin-releasing peptide messenger ribonucleic acid: neuroanatomical localization in rat brain by in situ hybridization with synthetic oligodeoxynucleotide probes. Neurosci Lett 137:123-128.

Harrington ME, Rusak B (1986) Lesions of the thalamic intergenicu- late leaflet alter hamster circadian rhythms. J Biol Rhythms 1:309325.

Hill JM, Agoston DV, Gressens P, McCune SK (1994) Distribution of VIP mRNA and two distinct VIP binding sites in the developing rat brain: relation to ontogenic events. J Comp Neurol 342:186-205.

Huang M, Rorstad OP (1990) PHI preferentially binds to VIP receptors in normal rat tissues. Peptides 11:1015-1020.

Ibata Y, Takahashi Y, Okamura J, Kawakami F, Terubayashi H, Kubo T, Yanaihara N (1989) Vasoactive intestinal polypeptide (VIP)-like immunoreactive neurons located in the rat suprachiasmatic nucleus receive a direct retinal projection. Neurosci Lett 97:1-5.

Johnson RF, Moore RY, Morin LP (1988) Loss of entrainment and anatomical plasticity after lesions of the hamster retinohypothalamic tract. Brain Res 460:297-313.

Kalsbeek A, Teclemariam-Mesbah R, Pevet P (1993) Efferent projections of the suprachiasmatic nucleus in the golden hamster (Mesocricetus auratus). J Comp Neurol 332:293-314.

Kupfermann I (1991) Functional studies of cotransmission. Physiol Rev $/ 1: 683-1 / 32$.

Ladenheim EE, Jensen RT, Mantey SA, McHugh PR, Moran TH (1990) Receptor heterogeneity for bombesin-like peptides in the rat central nervous system. Brain Res 537:233-240.

Ladenheim EE, Jensen RT, Mantey SA, Moran TH (1992) Distinct distributions of two bombesin receptor subtypes in the rat central nervous system. Brain Res 593:168-178.

Ladenheim EE, Jensen RT, Mantey SA, Taylor JE, Coy DH, Moran TH (1993) Bombesin receptor antagonists differentiate receptor subtypes in rat brain. Eur J Pharmacol 235:121-125.

Lorén I, Emson PC, Fahrenkrug J, Björklund A, Alumets J, Håkanson R, Sundler F (1979) Distribution of vasoactive intestinal polypeptide in the rat and mouse brain. Neuroscience 4:1953-1976.

Martin J-L, Dietl MM, Hof PR, Palacios JM, Magistretti PJ (1987) Autoradiographic mapping of [mono[ ${ }^{125}$ I]iodo-Tyr ${ }^{10}$, MetO $\left.{ }^{17}\right]$ vasoactive intestinal peptide binding sites in the rat brain. Neuroscience 23:539-565.

McKillop JM, Foy WL, Johnston CF, Shaw C, Murphy RF, Buchanan $\mathrm{KD}$ (1988) Gastrin-releasing peptide (GRP) immunoreactivity in the rat retina: a radioimmunoassay, immunohistochemical and chromatographic study. Brain Res 447:239-245.

Meijer JH, Rietveld WJ (1989) Neurophysiology of the suprachiasmatic circadian pacemaker in rodents. Physiol Rev 69:671-707.

Mikkelsen JD, Fahrenkrug J (1994) Concentrations and distribution of vasoactive intestinal polypeptide (VIP), peptide histidine isoleucine (PHI) and peptide histidine valine (PHV) in the cerebral cortex and the suprachiasmatic nucleus of the mouse. Brain Res 656:95-107.

Mikkelsen JD, Larsen PJ, O’Hare MMT, Wiegand SJ (1991) Gastrin releasing peptide in the rat suprachiasmatic nucleus: an immunohistochemical, chromatographic, and radioimmunological study. Neuroscience 40:55-66.

Mikkelsen JD, Larsen PH, Sørensen GG, Woldbye D, Bolwig TG, Hastings MH, Ebling FJP (1994) A dual-immunocytochemical method to localize $c$-fos protein in specific neurons based on their content of neuropeptides and connectivity. Histochemistry 101:245-251.

Moody TW, O'Donohue TL, Jacobowitz DM (1981) Biochemical localization and characterization of bombesin-like peptides in discrete regions of rat brain. Peptides 2:75-79.

Moody TW, Getz R, O’Donohue TL, Rosenstein JM (1988) Localization of receptors for bombesin-like peptides in the rat brain. Ann NY Acad Sci 547:114-129.

Moore RY (1973) Retinohypothalamic projection in mammals: a comparative study. Brain Res 183:458-463.

Okamura H, Ibata Y (1994) GRP immunoreactivity shows a day-night difference in the suprachiasmatic nuclear soma and cfferent fibers: comparison to VIP immunoreactivity. Neurosci Lett 181:165-168.

Okamura H, Murakami S, Uda K, Sugano T, Takahashi Y, Yanaihara C, Yanaihara N, Ibata Y (1986) Coexistence of vasoactive polypeptide (VIP)-, peptide histidine isoleucine (PHI)-, and gastrin-releasing peptide (GRP)-like immunoreactivity in neurons of the rat suprachiasmatic nucleus. Biol Res 7:295-299.

Okamura H, Takahashi Y, Terubayashi, Hamada S, Yanaihara N, Ibata Y (1987) VIP-like immunoreactive neurons and retinal projections in the rat suprachiasmatic nucleus. Biol Res 8:253-262.

Panula P, Yang H-YT, Costa E (1984) Comparative distribution of bombesin/grp- and substance P-like immunoreactivities in rat hypothalamus. J Comp Neurol 224:606-617. 
Peters RV, Zoeller RT, Hennessey AC, Stopa EG, Anderson G, Albers HE (1994) The control of circadian rhythms and the levels of vasoactive intestinal polypeptide mRNA in the suprachiasmatic nucleus are altered in spontaneously hypertensive rats. Brain Res 639:217227.

Pickard GE (1982) The afferent connections of the suprachiasmatic nucleus of the golden hamster with emphasis on the retinohypothalamic projection. J Comp Neurol 211:65-83.

Piggins HD, Rusak B (1993a) Electrophysiological effects of pressureejected bombesin-like peptides on hamster suprachiasmatic nucleus neurons in vitro. J Neuroendocrinol 5:575-581.

Piggins HD, Rusak B (1993b) Gastrin-releasing peptide (GRP $\left.{ }_{1-27}\right)$ phase-shifts the mammalian circadian pacemaker. Soc Neurosci Abstr 19:1488.

Piggins HD, Antle M, Rusak B (1994a) Injections of GRP into the suprachiasmatic nucleus induce phase-shifts regardless of constant lighting conditions. Soc Res Biol Rhythms Abstr 4:90.

Piggins HD, Cutler DJ, Rusak B (1994b) Effects of ionophoretically applied bombesin-like peptides on hamster suprachiasmatic nucleus neurons in vitro. Eur J Pharmacol 271:413-419.

Pinnock RD, Reynolds T, Woodruff GN (1994) Different types of bombesin receptors on neurons in the dorsal raphe nucleus and the rostral hypothalamus in rat brain slices in vitro. Brain Res 653:119-124.

Robinson ML, Fuchs JL (1993) [ ${ }^{125}$ I]Vasoactive intestinal polypeptide binding in rodent suprachiasmatic nucleus: developmental and circadian studies. Brain Res 605:271-279.

Roth KA, Weber E, Barchas JD (1982) Distribution of gastrin releasing peptide-bombesin-like immunostaining in rat brain. Brain Res 251: 277-282.

Rusak B, Zucker I (1979) Neural regulation of circadian rhythms. Physiol Rev 59:449-527.

Shaffer MM, Moody TW (1986) Autoradiographic visualization of CNS receptors for vasoactive intestinal polypeptide. Peptides 7:283288.
Shinohara K, Tominaga K, Isobe Y, Inouye ST (1993) Photic regulation of the peptides located in the ventrolateral subdivision of the suprachiasmatic nucleus of the rat: daily variations of vasoactive intestinal polypeptide, gastrin-releasing peptide, and neuropeptide Y. J Neurosci 13:793-799.

Swanson LW, Cowan WM, Jones EG (1974) An autoradiographic study of the efferent connections of the ventral geniculate nucleus in the albino rat and cat. J Comp Neurol 160:1-12.

Takahashi JS, DeCoursey PJ, Bauman L, Menaker M (1984) Spectral sensitivity of a novel photoreceptive system mediating entrainment of mammalian circadian rhythms. Nature 308:186-188.

Tang KC, Pan J (1993) Stimulatory effects of bombesin-like peptides on suprachiasmatic nucleus neurons in brain slices. Brain Res 614: 125-130.

Usdin TB, Bonner TI, Mezey I (1994) Two receptors for vasoactive intestinal polypeptide with similar specificity and complementary distributions. Endocrinology 135:2662-2680.

van den Pol AN, Gorcs T (1986) Synaptic relationships between neurons containing vasopressin, gastrin-releasing peptide, vasoactive intestinal polypeptide, and glutamate decarboxylase immunoreactivity in the suprachiasmatic nucleus: dual ultrastructural immunocytochemistry with gold-substituted silver peroxidase. J Comp Neurol 252:507-521.

Wada E, Way J, Lebacq-Verheyden A-M, Battey JF (1989) Neuromedin $B$ and gastrin-releasing peptide mRNAs are differentially distributed in the rat nervous system. J Neurosci 10:2917-2930.

Zhang DX, Rusak B (1989) Photic sensitivity of geniculate neurons that project to the suprachiasmatic nuclei or contralateral geniculate. Brain Res 504:161-164.

Zoeller RT, Broyles B, Earley J, Anderson ER, Albers HE (1992) Cellular levels of messenger ribonucleic acids encoding vasoactive intestinal polypeptide and gastrin-releasing peptide in neurons of the suprachiasmatic nucleus exhibit distinct 24 -hour rhythms. J Neuroendocrinol 4:119-124. 